attended that the sections have held for many years, the interest never seemed to flag and, while no wonderful contributions were made to scientific knowledge, every one went away feeling either that he had gained much information as to the other man's point of view concerning scientifically instructing engineering students in mathematics and of the wishes and needs of the engineering instructor, or that he appreciated more the quality of work that was now being done by teachers of mathematics in engineering colleges.

WM. T. MAGRUder, Secretary, Section D

\section{PRESENT CONDITION OF MATHEMATIOAL INSTRUCTION FOR ENGINEERS IN AMERICAN COLLEGES ${ }^{1}$}

OuR country has witnessed in recent years a most marvelous industrial expansion and development. Along with this movement has come a rapidly increasing demand for trained men, equipped with all that science can contribute, to direct and carry forward this development of our natural resources and our industrial power. In meeting this demand our technical schools have experienced a remarkable growth, and not a little of the educational thought and activity of the country is being directed toward the problems connected with technical instruction. Wellequipped engineering schools have grown up in the larger centers of population and most of the larger state universities now include strong engineering departments. Mathematics is so fundamental to all of this work, and so large a proportion of the students now receiving mathematical instruction in this country anticipate making

${ }^{1}$ Opening address before the joint meeting of Sections $A$ and D of the American Association for the Advancement of Science with the Chicago Section of the American Mathematical Society for the discussion of the topic "Mathematical Training for Engineers." use of it later in connection with engineering work, that it has been thought best by the Chicago Section of the American Mathematical Society to invite to a joint discussion of the "Mathematical Training of Engineering Students," representatives from some of the leading engineering schools and some of those consulting engineers whose wide experience has brought them into contact with demands of actual practise.

That we may all know what the actual. conditions are with respect to this instruction and consequently have some common basis for our discussion and our conclusions, I have been asked to present a statement of the work in mathematics which is now being given to engineering students.

As the basis of our consideration, I have selected seventeen institutions where engineering work is an important feature. Of these, eight give their attention largely or exclusively to technical work, and the remaining institutions have strong engineering departments; so that the mathematical work given in these institutions may be said to fairly represent the preparation in this subject for engineering students in American institutions.

The three most important factors entering into the consideration of our topic are: the entrance requirements, the requirements for graduation, and the qualifications of the instructional force.

As will be seen from Table I., all of these seventeen institutions require for entrance algebra through quadratics, together with plane and solid geometry. Five of the institutions require plane trigonometry, while at several others it may be counted for entrance if the student so elects. It will be observed that four institutions require elementary algebra through progressions, four require the subject of logarithms, and two, Sheffield and Cornell, require the whole of college algebra. 
TABLE I

\begin{tabular}{|c|c|c|c|c|c|c|c|c|c|c|c|c|c|c|c|c|c|}
\hline & 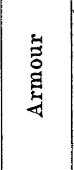 & 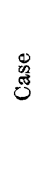 & $\begin{array}{l}\bar{\Xi} \\
\text { : } \\
8\end{array}$ & 苛 & 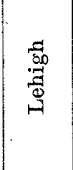 & 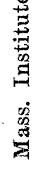 & 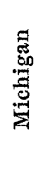 & 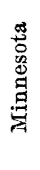 & 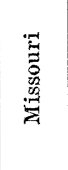 & 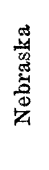 & 总 & 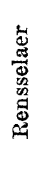 & $\begin{array}{l}0 \\
\text { : } \\
\text { ch }\end{array}$ & 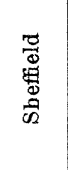 & 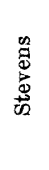 & 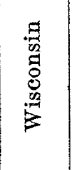 & 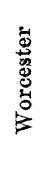 \\
\hline $\begin{array}{l}\text { Algebra ........... } \\
\text { Plane Geome- } \\
\text { try ............ } \\
\text { Solid Geome- }\end{array}$ & $\begin{array}{c}\text { p.L. } \\
6\end{array}$ & “ & $\begin{array}{c}\text { Coll. } \\
\text { Alg. } \\
،\end{array}$ & $\begin{array}{l}q \\
\text { " }\end{array}$ & $\begin{array}{l}\overline{\text { Adv. }} \\
\text { Alg. } \\
6\end{array}$ & $\begin{array}{l}\mathrm{p} \\
\text { ، }\end{array}$ & $\begin{array}{l}q \\
\text { ، }\end{array}$ & "، & q.L. & $\begin{array}{l}\mathrm{L} \\
\text { ، }\end{array}$ & $\begin{array}{l}q \\
\text { " }\end{array}$ & " & $\begin{array}{l}q \\
\text { ، }\end{array}$ & $\begin{array}{c}\text { Coll. } \\
\text { Alg. } \\
\text { ، }\end{array}$ & $\begin{array}{l}p \\
"\end{array}$ & p L. & $\begin{array}{l}p \\
\text { " }\end{array}$ \\
\hline $\begin{array}{c}\text { try ........... } \\
\text { Plane Trig- } \\
\text { onometry.... } \\
\text { Spherical trig- } \\
\text { onometry..... }\end{array}$ & ، & "6 & $\begin{array}{l}\text { ، } \\
\text { ، }\end{array}$ & " & ، & " & 6 & " & e & " & " & 6 & " & $\begin{array}{l}\text { " } \\
\text { " }\end{array}$ & "، & " & "، \\
\hline
\end{tabular}

$\mathrm{p}=$ through progressions, $\mathrm{q}=$ through quadratics, $\mathrm{L}=$ logarithms, $\mathrm{e}=$ elective.

There is a general tendency over the country to increase rather than diminish the entrance requirements in mathematics. Several institutions have recently done so, and at number of others there is a feeling that both trigonometry and college algebra should be required. This disposition to increase the entrance requirements has come about not so much because of a feeling that these subjects can be as well or better taught in the secondary schools, but because of a feeling on the part of the technical schools that the entrance requirements should be made as high as possible in order to give room in the curriculum for those professional and technical branches which are now deemed essential. It may well be questioned whether we are not in some danger of going too far in increasing the requirements. I am sure that we should all agree that the guiding principles should be the limitations of the secondary school program and the ability of the pupil at that stage of his maturity to readily grasp in a comprehensive manner the subjects presented. For example, the advisability of adding college algebra to the entrance requirements is certainly open to the objection that portions of it are clearly be- yond the maturity of the average high school pupil, and the introduction of plane trigonometry would seem inadvisable in the average high school on the accredited list of the state universities of the Mississippi Valley. When either of the fundamental principles mentioned is violated, we shall have coming to our freshman class, students with a decided and a justifiable dislike for anything mathematical. Rather than to encounter this danger, it would be far better to extend the engineering course over five years or to require a year of college work in science and mathematics before the student enters upon his technical course. In this connection, it is interesting to note that the University of Minnesota has recently extended its course to five years for students in civil, mechanical and electrical engineering, distributing the required work in mathematics throughout the first four years.

The writer does not share with some the feeling that a greater uniformity in entrance requirements is either desirable or of any particular consequence. Each institution, and especially the state institutions, must take into consideration what the secondary schools contributary to it can do satisfactorily and then shape its 
work accordingly. The size of the city, the general interest in educational affairs, the trend which local interests give to the public-school curriculum, all tend to make it possible to accomplish in one community, or in one section of the country, what would be quite impossible in another. We must accept our students with such preparation as our normal constituency can give, stimulated, to be sure, and to a certain extent guided by the higher institution of learning, and build our technical courses upon that preparation as best we may.

More general dissatisfaction is expressed with reference to the preparation of our students in algebra than in any other subject. This comes from both eastern and western institutions as well as from those of the Mississippi Valley. At the University of Illinois last year forty per cent. of the freshman class failed to pass a quiz covering the main points of elementary algebra and that after a two weeks' review of the subject, and twenty-three per cent. of the class failed on a second examination some weeks later. Of the one hundred and ninety students who failed on the first test, seventy-four per cent. entered the university without conditions from schools where the work had been examined and approved by the high-school visitor. The poor results which we get in algebra are not due, in my estimation, exclusively to poor instruction in the subject or to the lack of attention in the high school. It is the one subject in mathematics which is begun in the high school and completed in the college course. Often the highschool algebra is completed in the sophomore year and then not taken up again until the student enters upon his technical course. All know how difficult it is to retain the details of any course of study during an interval of several years in which the subject has been but little used. That this lapse of time between the completion of the high-school work and the beginning of the college work is an important element in the case is shown by the fact that of the one hundred and ninety failures mentioned over fifty per cent. had not had algebra for at least four years, and only ten per cent. had studied the subject the year before.

A substantial gain would be made if we should urge upon the high schools the desirability of putting the last half year devoted to algebra in the senior year of the high-school curriculum and include in that work the more difficult parts of the subject as well as a general review of the parts presented earlier. This arrangement has become quite common in Illinois, and the best argument that can be presented in favor of such an arrangement is that of the one hundred and ninety cases of failure cited over sixty-three per cent. had completed the work in the sophomore year and less than eight per cent. had had any work in algebra in the senior year. Similar records have been kept at Illinois for the past seven or eight years and the data given are typical of the other years.

Unfortunately, we can have no assurance that when a student has once mastered a subject, he will forever afterwards retain it. Neither can we hope that algebra will ever be anything other than the weakest place in the preparation of our students so long as the present division of the subject so largely prevails. It is a situation which we must accept, and the only thing we can do is to make such recommendations as will tend to reduce the number of fatalities as the boy passes from his secondary school to his technical course. The technical school must expect to commence its course in college algebra by a brief review of the important points covered in the high school, by taking a back-stitch, so to speak, into the work already done. Most of the western schools admit by cer- 
tificate to the freshman class, and when a pupil is once graduated from an accredited school, he has earned the right to commence upon his technical course. At the University of Illinois, the problem has been solved by saying to the freshmen in mathematics that while there is no disposition to deprive them of their entrance credit, the department of mathematics may nevertheless determine the conditions under which credit in college algebra can be secured. Accordingly, those students who fail to pass the review quiz are required to take two additional hours per week in the subject for the remainder of the semester in order to earn the same credit that is given to others at the close of the course. This has the advantage of placing all of the students practically upon the same basis, so far as attainments in algebra are concerned, when they enter upon the second semester's work.

A somewhat similar plan as that outlined here is followed also at the University of Wisconsin, and perhaps at other institutions. It will be seen from Table I. that a large number of technical schools are now requiring work in logarithms for entrance. This might very well be introduced in connection with theory of exponents and used with advantage in highschool physics. It is also gratifying to observe that the more recent texts on algebra provide work in the use of the graph and in the plotting of curves. It is very desirable that the work in elementary algebra, including the work of curve-plotting, should also include applications to some of the simpler phenomena studied in the high-school course in physics, and this again is made a feature in some of the more recent texts. Such an arrangement affords an additional reason for putting some of the work in algebra late in the high-school course in order that it may follow rather than precede the work in physics, thus making it possible to introduce a wider range of physical applications than could otherwise be done.

In Table II. is shown the number of restrictions given in each of the various mathematical subjects required of engineering students. The average number given to each subject for the seventeen institutions is approximately as follows: college algebra 50, plane trigonometry 46 , analytic geometry 80, and calculus 130 . In a number of the institutions named, spherical trigonometry is taught by one of the engineering departments, usually the civil-engineering department, in connection with its applications to geodesy. The number of recitations assigned to calculus usually includes also a short course in differential equations. In two cases where a course of more than usual length in the subject is given for the students of a particular engineering department, the subject has been listed separately. ${ }^{2}$ One institution, Rose Polytechnic Institute, is unique among strictly engineering schools in offering throughout the four years of undergraduate work a rather large amount of elective mathematics, including short courses in advanced calculus, least squares, projective geometry and quaternions. In all of the universities listed, and at the Massachusetts Institute of Technology the mathematical department offers a rather wide range of advanced subjects, all of which are open to engineering students so far as the demands of their technical course will permit.

By a study of Table II., it will be seen that a considerable difference exists in the amount of attention given to the various subjects. In making comparisons in algebra and trigonometry, however, the difference in entrance conditions must be

${ }^{2}$ Table III. shows the number of recitations given to differential equations in each case when that subject was reported separately. 
TABLE II

\begin{tabular}{|c|c|c|c|c|c|c|c|c|c|c|c|c|c|c|c|c|c|}
\hline & 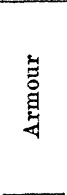 & $\begin{array}{l}\mathscr{\Xi} \\
\text { ¿ू }\end{array}$ & 离 & 昜 & 节 & 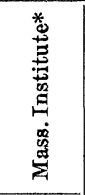 & 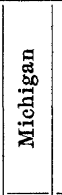 & 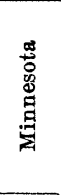 & 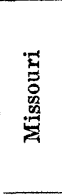 & 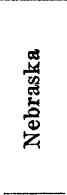 & 芯 & 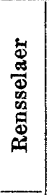 & 总 & 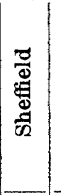 & 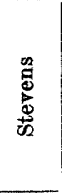 & 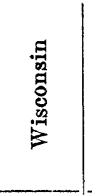 & 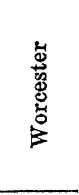 \\
\hline Algebra .......... & 65 & 45 & & 55 & $\left\{\begin{array}{l}40 \\
\text { C.E. }\end{array}\right.$ & 30 & 36 & 70 & 36 & 36 & 90 & 55 & $\left.\begin{array}{c}72 \\
{[18]}\end{array}\right]$ & & 15 & $\int 007$ & 64 \\
\hline $\begin{array}{r}\text { Plane Trigo- } \\
\text { nometry...... } \\
\text { Spherical Trig- } \\
\text { onometry..... }\end{array}$ & & $\begin{array}{l}60 \\
10\end{array}$ & & 35 & $\left\{\begin{array}{l}22 \\
\mathrm{C.E}\end{array}\right.$ & $\left\{\begin{array}{l}30 \\
10 \\
\text { C.E. }\end{array}\right.$ & & $\begin{array}{l}45 \\
25\end{array}$ & $\begin{array}{l}45 \\
10\end{array}$ & 54 & $\begin{array}{l}70 \\
20\end{array}$ & $\begin{array}{l}29 \\
11\end{array}$ & $\begin{array}{c}54 \\
{[18]}\end{array}$ & & 10 & $\{90\}$ & $\begin{array}{r}45 \\
3\end{array}$ \\
\hline $\begin{array}{r}\text { Analytic Ge - } \\
\text { ometry......... }\end{array}$ & 55 & 100 & 60 & 90 & $\left\{\begin{array}{l}80 \\
58 \\
\text { C.E. }\end{array}\right.$ & 60 & 108 & 110 & 90 & 108 & 72 & 60 & $\begin{array}{c}54 \\
{[18]}\end{array}$ & 90 & 69 & 90 & 64 \\
\hline Calculus.......... & 155 & 125 & 120 & 144 & $\left\{\begin{array}{l}108 \\
96 \\
\text { C.E. }\end{array}\right.$ & 90 & 144 & 110 & 180 & 126 & 144 & 70 & $\begin{array}{l}180 \\
{[72]}\end{array}$ & 100 & 144 & $\left\{\begin{array}{l}180 \\
160 \\
\text { C.E. }\end{array}\right.$ & 96 \\
\hline Least squares.. & & $\left\{\begin{array}{l}48 \\
\text { C.E. }\end{array}\right.$ & & & & & & & & & & & [18] & & & & \\
\hline $\begin{array}{l}\text { Vector Anal- } \\
\text { ysis .................. }\end{array}$ & & & & & & & & & & & & & & & & & $\left\{\begin{array}{l}32 \\
\mathrm{C} . \mathrm{E}\end{array}\right.$ \\
\hline $\begin{array}{c}\text { Projective Ge- } \\
\text { ometry ......... } \\
\text { Quaternions.... } \\
\text { Differential } \\
\text { Equations.... }\end{array}$ & & $\left\{\begin{array}{l}34 \\
\text { M.E. }\end{array}\right.$ & & & & $\left\{\begin{array}{l}45 \\
\text { E.E. }\end{array}\right.$ & & & & & & & $\begin{array}{l}{[18]} \\
{[18]}\end{array}$ & & & & \\
\hline
\end{tabular}

C. E.= civil engineers, M. E. = mechanical engineers, E. E. = electrical engineers, []$=$ elective.

* Massachusetts Institute of Technology now offers a course which combines the instruction in algebra, analytic geometry and calculus rather than teaching these subjects as separate branches. In tables II. and III., the distribution of time formerly given to these subjects is indicated as showing better the relative emphasis placed upon each.

taken into consideration. The amount of work given in algebra ranges from fifteen recitations at Stevens Institute, with an entrance requirement of elementary algebra through progressions, to ninety recitations at Purdue with a requirement of elementary algebra through quadratics for entrance. Likewise the work in plane trigonometry ranges from thirty recitations at the Massachusetts Institute to seventy at Purdue. Analytic geometry and calculus are naturally the most important subjects for engineers in the mathematical curriculum. One would naturally expect to find a greater uniformity here. This, however, is not the case. In analytic geometry, it will be noticed that Armour Institute requires but fifty-five recitations, while the University of Minnesota gives one hundred and ten recitations to the sub- ject. Again in calculus the work varies from seventy recitations at Rensselaer to a maximum of one hundred and eighty at Missouri, Wisconsin and Rose. A word should be said, perhaps, concerning the number of recitations recorded in the case of Rensselaer. The department of mathematics of that institution reports that the recitations are from an hour and a quarter to an hour and a half in length and that the efficiency of the work is still further increased by the fact that but two academic studies are carried simultaneously.

It will be of interest also to compare the total amount of time spent upon mathematics at these various institutions. As will be seen from Table III., this ranges from one hundred and eighty recitations at Cornell to three hundred and ninety-six at Purdue. In making this comparison, 
TABLE III

\begin{tabular}{|c|c|c|c|c|c|}
\hline Institution & Freshman & Sophomore & Junior & Senior & Total \\
\hline Armour ..... & AI $65 ;$ An $55 ;$ C 50 & C 85 ; Diff. eqs. 20 & & & 275 \\
\hline Case. ......... & $\operatorname{AI} 45 ; \operatorname{Tr} 70 ; \operatorname{An} 55$ & An $45 ; C 125$ & Diff. eqs. 34 (E.E.) & $\begin{array}{c}\text { Least squares } \\
48 \text { (C.E.) }\end{array}$ & $\begin{array}{l}\text { M.E. ; } 340 \\
\text { E.E.; } 374 \\
\text { C.E.; } 388\end{array}$ \\
\hline Cornell....... & An $60 ;$ C 120 & C 144 & & & 180 \\
\hline Lehigh ...... & $\begin{array}{l}\text { An } 80 ; \mathrm{C} 108 \\
\text { Al } 40 ; \operatorname{Tr} 22 ; \mathrm{M} 25\end{array}$ & (C.E.) An 58 ; C 96 & & & $\begin{array}{l}324 \\
\text { E.E.; M.E.; } 188 \\
\text { C.E.; } 241\end{array}$ \\
\hline Mass. Inst.. & AI $30 ; \operatorname{Tr} 30 ;$ An 60 & $\begin{array}{l}\text { C } 90 ; \\
\text { Sph Tr } 10 \text { (C.E.) }\end{array}$ & Diff. eqs. 45 (E.E.) & & $\begin{array}{l}\text { M.E. ; } 210 \\
\text { E.E.; } 255 \\
\text { C.E.; } 220\end{array}$ \\
\hline Michigan... & Al $36 ;$ An 108 & C 126 & Diff. eqs. 18 & & 288 \\
\hline $\begin{array}{l}\text { Minnesota.. } \\
\text { Missouri.... }\end{array}$ & $\begin{array}{l}\text { Al } 70 ; \operatorname{Tr} 70 ; \operatorname{An} 40 \\
\text { Al } 36 ; \operatorname{Tr} 55 ; \operatorname{An} 90\end{array}$ & $\begin{array}{l}\text { An } 70 ; \text { C } 110 \\
\text { C } 180\end{array}$ & & & $\begin{array}{l}360 \\
360\end{array}$ \\
\hline Nebraska ... & $\begin{array}{l}\text { Al } 36 ; \operatorname{Tr} 54 ; \text { An } 72 ; \\
\quad \text { C } 18\end{array}$ & An $36 ;$ C 108 & & & 324 \\
\hline Purdue...... & $\mathrm{AI} 90 ; \operatorname{Tr} 90$ & An $72 ; C 72$ & C 72 & & 396 \\
\hline Rensselaer.. & Al $45 ; \operatorname{Tr} 40 ;$ An 39 & An $21 ; C 70$ & & & 225 \\
\hline Rose.......... & $\begin{array}{l}\text { AI } 72 ; \operatorname{Tr} 54 ; \text { C } 36 \\
\text { [S Tr 18]; [Proj. } \\
\text { Geom. 18] [AI 18] }\end{array}$ & $\begin{array}{l}\text { An 54; C } 90 \\
\text { [Quat 18] [An 18] }\end{array}$ & $\begin{array}{l}\text { An Dyn } 54 \text { (calculus) } \\
\text { [C 72] } \\
\text { [Least squares } 18]\end{array}$ & & $\begin{array}{l}360 \\
{[180]}\end{array}$ \\
\hline Sheffield .. & An 90 & C 100 & & $\begin{array}{c}\text { [Probs. and } \\
\text { computing] }\end{array}$ & $\begin{array}{l}190 \\
\text { [Probs. ] }\end{array}$ \\
\hline Stevens...... & $\begin{array}{l}\log 15 ; \underset{\operatorname{Sph}}{\operatorname{Tr} 10} \text {; } 43 ; \mathrm{C} 30\end{array}$ & An $26 ;$ C 86 & Diff. eqs. 28 & & 238 \\
\hline Wisconsin .. & $\mathrm{Al}$ and $\operatorname{Tr} 90 ; \operatorname{An} 90$ & $\begin{array}{l}\text { C } 160 \text {; } \\
\text { Diff. eqs. } 20 \text { (M.E.; } \\
\text { E.E.) }\end{array}$ & & & $\begin{array}{l}\text { M.E.; E.E.; } 360 \\
\text { C.E.; } 340\end{array}$ \\
\hline Worcester... & Al $64 ; \operatorname{Tr} 48$ & An $64 ;$ C 96 & Vect. and 32 (E.E.) & & $\begin{array}{l}272 \\
\text { E.E.; } 304\end{array}$ \\
\hline
\end{tabular}

$\mathrm{Al}=$ algebra, $\mathrm{An}=$ analytic geometry, $\mathrm{C}=$ calculus, $\mathrm{Tr}=$ trigonometry, $\mathrm{M}=$ mensuration, Quat $=$ quaternions, An Dyn = analytical dynamics, [ ] = elective.

we should again take into consideration the difference in entrance requirements. When this is done, the difference is more apparent than real. For example, if we add to the number of recitations given at Cornell the number of recitations given at Purdue to college algebra and trigonometry, which are required for entrance at Cornell as compared with three hundred and ninety-six at Purdue.

It would seem that the technical schools generally might well afford to make more ample provision for elective mathematics. Such courses as spherical trigonometry, least squares, differential equations, might well be placed in such a list. In this way certain subjects which are desirable for some branches of engineering, but not so essential for others, could be taken by those students interested. Sheffield offers as an elective another course which might be given with advantage at other technical schools, namely, a course in scientific computation in which the use of modern calculating machines of various kinds is explained and made use of. It would also be well if the stronger institutions could go still farther and introduce elective 
courses in spherical harmonics, vector analysis, theory of functions and the mathematical theory of heat, electricity, etc., to the end that the student with exceptional mathematical ability might lay a broader foundation for the theoretical side of engineering. In this connection, it may well be questioned whether the technical schools of this country are in general offering sufficient opportunity for that training which has made, it possible for such men as Steinmetz, Osborne Reynolds and Stodola to accomplish the work which has made them famous.

Table III. shows also the sequence and the distribution by years of the required work in mathematics. We are quite as much interested, however, in the character as in the amount and distribution of the mathematical instruction given to engineering students. The close observer will have noticed the change which has been made and is now being made in this respect. In recent years there has swept over the country a wave of enthusiastic discussion concerning a closer and better correlation of mathematics with the physical sciences. This has been due for the most part to the influence felt in this country of the Perry movement in England. Much is to be learned from this movement, and still more is to be avoided. The discussions which have arisen from it have on the whole had a beneficial effect upon the teaching of mathematics both in America and in England.

It has first of all led to the introduction into our text-books, and still more generally into our teaching, of a very much better selection of problems-problems which widen the student's fund of information of physical phenomena and apply the mathematical principles which he is acquiring more extensively than was formerly the case to the physical laws with which he is familiar. Such problems as the following, taken from a recent number of an educational journal purporting to serve the interests of mathematical teachers in the secondary schools, is no longer thought to be in good form by our best instructors:

"I bought 674,867 sheep at less than $\$ 10$ per head; I paid for them in ten-dollar bills and received back in change $\$ 7.39$. How many bills did I give?"

Need I call attention to the absurdity of putting such problems into the hands of pupils? How many farmers in any woolproducing state of the country ever even saw that many sheep in his entire life, and, should he have occasion to buy them, would for a moment think of paying for them by counting out 663,395 ten-dollar bills. So long as such problems are given out for the consideration of pupils, just so long we may expect even the best of them to ask the question so often heard in our algebra classes: "What is all of this 'stuff' good for, anyway?"

Contrast with this problem the following, taken at random from an algebra recently published:

"Two boys, $A$ and $B$, having a $30-1 b$. weight and a teeter board, proceed to determine their respective weights as follows: They find that they balance when $B$ is 6 feet and $A 5$ feet from the fulcrum. If $B$ places the $30-1 b$. weight on the board beside him, they balance when $B$ is 4 and $A$ is 5 feet from the fulcrum. How heavy is each boy?"

In solving this problem the boy has learned just as much mathematics as in solving the first. In addition, his mathematics has been brought into contact with a fundamental physical law, and incidentally he is made to feel that, after all, his mathematics is of consequence to him in solving the sort of questions in which he 
is interested or is likely to have experience with in the future.

As has been pointed out, a change in the character of the problems is gradually taking place in our mathematical texts. Perhaps a word of caution should be given lest we go too far in the opposite direction, by introducing problems which require a technical knowledge and experience beyond the comprehension of our students. Perry's calculus is a conspicuous illustration of this danger. The subjects discussed in that book would form a good sequel to a certain work in engineering, but the book seems to be hardly suited to meet the needs of American schools as a preparation for engineering study. We should aim to make the mathematical work practical and in harmony with engineering practise, but without making it at the same time technical in its applications, or without going too far afield by teaching mathematical physics.

Another improvement which has recently become noticeable in the teaching of mathematics in this country is the breaking down of the traditional barriers between the different branches and a corresponding closer correlation of the different subjects in the mathematical curriculum. In several of our institutions the sharp division of freshman work into algebra, trigonometry, and analytic geometry is being more or less disregarded and these subjects taught as a single unit. It is thought that the student is thus enabled to grasp more readily these subjects as a whole, and that the instructor can introduce much earlier the principles of analytic geometry and of calculus and postpone to the later part of the course those topics which are relatively difficult and not so essential to the elementary work of the course.

This plan is now being followed somewhat closely at the University of Wisconsin. In the first semester fifteen or twenty recitations are devoted to the elementary portions of trigonometry. This is followed by work in algebra, including the theory of complex numbers, using trigonometry and a large amount of graphic work, and the elementary principles of analytic geometry. In this work trigonometric computation and the use of the slide rule form an important part. In the second semester the algebra and trigonometry are continued and combined with the essentials of analytic geometry.

This correlation of the work of the freshman year seems to have been most thoroughly worked out at the Massachusetts Institute of Technology, where Professors Woods and Bailey have recently prepared a text covering the work given there in the freshman year, excluding, however, trigonometry. The indications are that other institutions are also contemplating a revision and better correlation of the work of the first year.

In some of the recent books, the sharp division of the calculus into differential and integral calculus is done away with, thus making it possible to introduce the student to a wide range of easy applications at an early point in the course and to relegate to its proper place some of the more difficult parts of the differential calculus. There is a tendency also to introduce the methods of the calculus earlier and make them the basis of portions of the analytic geometry. For example, Rose Polytechnic Institute gives a short course of thirty-six recitations in the subject before analytic geometry is taken, and what is accomplished there in this formal way is undertaken at other institutions by introducing into the analytics the elementary notion of derivatives or by teaching the two subjects simultaneously.

While all are agreed that for engineers mechanics should stand in a close and vital relation to the calculus, that in fact it is 
the principal reason for teaching calculus, not all are agreed, however, as to the best method of accomplishing this purpose. Some would maintain that it should be taught by the mathematical department and in connection with calculus; others and perhaps the larger number feel that it should be given by the engineering departments and made to follow and supplement the calculus, giving the student his first real introduction into the applications of his mathematics to the fundamental principles underlying all engineering courses. However this may be, there is little doubt that more applications to mechanics should be introduced into the course in calculus than is now usually the case, even to the exclusion, if need be, of some of the applications to geometry frequently given. Problems in work, energy and stress form just as legitimately an integral part of a course in calculus as problems in order of contact, asymptotes or envelopes. The applications to geometry and to mechanics should be given about the same relative importance in a well-balanced course in calculus.

Descriptive geometry is another subject in the engineering course which might well be revised and made more mathematical in its treatment. It is to be regretted that the subject has in this country degenerated into little more than mechanical drawing. It would be greatly improved for engineers, as well as the general student, if we should inject into it something of the scientific spirit given it in European schools.

No presentation of the subject under discussion would be complete without some consideration of the preparation which the teacher of mathematics has, or should have, who is to teach the subject to engineering students. There is a strong feeling in some quarters that such an instructor should be a trained engineer in order that he may the better appreciate the kind of applications which are best suited to the training of an engineer and to make sure that the proper emphasis be placed upon those topics considered essential in such training. Some would go still farther and insist that even in the elementary courses in mathematics usually given in the first two years, the purpose and aim of the prospective engineer is so radically different from that of the general student that the content of the course itself should be very different from what is best suited to the student who elects mathematics as a part in a general education.

It goes without saying that we should eliminate from the courses for engineering students that which is non-essential, and we should make them as practical as we may by the generous use of those physical applications which will give the students both skill and facility in applying mathematics to such concrete cases as may arise later in his experience. On the other hand, it would be disastrous to go to the extent of teaching any of the principles of mathematics empirically or of permitting students to assume as already established formulas which he has merely to learn how to apply. We should avoid the danger of going too far in allowing the student to disregard the necessity of a formal demonstration and to regard lightly the logic and the philosophy of mathematics. What is needed first of all is the ability on the part of the student to think mathematically and to have not only a ready but an intelligent command of the fundamental principles of the subject. We should introduce the applications of mathematics not for the sole purpose of giving the student a foretaste of the things which are in store for him, but because such applications give him additional opportunity for gaining a clearer comprehension of mathematical processes and principles which might otherwise be hazy; and I wish to add that this is more 
essential for the sound training of the special student of mathematics with his limited opportunity for the application of his subject to physical phenomena than it is for the engineering student who in the future is to have opened up to him that wide range of applications which his technical studies provide. In other words, what is essential in the way of applications for the engineering student in the first two years of his mathematical work gives the very best training for the student who is taking mathematics as an element in a liberal education. The proper place for differentiation, so far as the content of the course is concerned, would seem to be after the completion of the course in calculus rather than before. I present this as a plea for the general student, that he should have more of the applications of his mathematics rather than that the engineering student should have less. Both should have thorough drill in the fundamental principles of the subject and in addition all of the applications of those principles which their limited experience and knowledge of physical phenomena will permit. No student, enginering or otherwise, should be led to regard his mathematical work in the same light in which a carpenter may properly regard his jack-plane, a mere tool with which to accomplish certain results; neither should the instructor teach mathematics in the spirit in which a skilled operator might regard a finely-equipped machine shop whose sole purpose is to make more machines. Both extremes are to be avoided in the early courses in mathematics. The opportunity for specialization and differentiation should come later; and any student who is not capable of grasping the fundamental principles of the mathematics usually required in an engineering course should not aspire to a bachelor's degree from a large university or technical school.

What training is essential or desirable, then, on the part of the mathematical instructor of engineering students to best accomplish the general results here set forth? There is no doubt that the ideal thing would be to take men who have completed an engineering course and later supplemented it by special work in mathematics. This, however, does not seem feasible because of the few who could be induced to take such a course of training. It would be quite impossible to induce a sufficient number of engineers to take up the teaching of mathematics to meet the demand, even if that seemed desirable. In most cases the boy enters the engineering course with the view of practising his profession when he has completed the course. As a rule he has little taste or inclination for teaching, and those few who can be induced to enter the less remunerative profession of teaching are absorbed, as indeed they should be, by the engineering departments of our technical schools. To put an engineering graduate at teaching mathematics without first having had special training in mathematics would be wholly undesirable. Such an instructor knows but little about pure mathematics beyond the elementary courses which he is presenting, and, what is even worse, often has but little interest. If he can be induced to take up in a serious way the study of mathematics, he is in a fair way of becoming a good teacher of the subject. I am thoroughly convinced that mathematics should be taught by mathematicians just as engineering should be taught by trained engineers; but the mathematical instructor who wishes to teach engineers should be familiar with the general field of applied mathematics-mechanics, strength of materials, thermodynamics, and in addition so much of the broader field of mathematical physics as possible.

While the mathematical instructor should have some knowledge of its applications, it 
is equally desirable that the teacher of engineering should from time to time both refresh and revise his knowledge of the fundamental things in mathematics, to the end that he may keep his methods up to date and adapt his teaching to the kind of mathematical instruction which his students have had and avoid those methods and those forms of expression which have long been out of use.

In closing, I wish to add that the rapid increase in engineering students has so greatly increased the demand for mathematical instructors having some knowledge of engineering that it would be highly desirable if more attention should be paid to the preparation of men for such positions. This can best be accomplished, perhaps, in those universities having large engineering departments by a closer correlating of the work of the mathematical department with theoretical work in engineering and mathematical physics. It is to be regretted that so little attention in this country is now being given to these two fields of mathematical activity. Institutions so situated as to undertake it should offer to its students graduate work in these lines in every respect worthy of a doctor's degree, and likewise to its instructors both opportunity and encouragement to do research work in this broad and fruitful field of human endeavor. EDGAR J. TOWNSEND

UNIVERSITY OF ILLINOIS

\section{INTERNATIONAL FISHERY CONGRESS, 1908}

THE Fourth International Fishery Congress will convene in the city of Washington, United States of America, from the twentysecond to the twenty-sixth of September, 1908 , to deliberate on important matters relating to fishing and fish culture and to submit propositions for the benefit of the fisheries to governments and to state, provincial and local authorities.
The congress will be organized and conducted in conformity with the decisions for the regulation of the international fishery congresses decreed in Paris in 1900.

The membership of the congress will consist of government, state, and provincial representatives, delegates from home and foreign societies, corporations and persons invited by the management of the congress, and persons at home and abroad who are deemed to have an interest in the purposes of the congress and express a wish to take part in it.

All members have the right to vote, to participate in the discussions, and to make independent propositions. In case a corporation should be represented by several delegates, the members of this delegation have the right to only one vote, which shall be cast by the delegate designated to the presiding officer. The delivery of the card of admission gives to members the right to take part in all the enterprises and excursions projected by the congress, to receive all the publications, and to wear the insignia of the congress. The members of the congress are required to conform to its regulations and decisions.

The membership fee is fixed at $\$ 2$ for each person, excepting the official representatives of governments, who become members by virtue of their credentials.

In response to invitations extended by the government of the United States, twelve national governments have already signified their purpose to be officially represented, and delegates have been appointed by the governors of many of the states of the United States. In view of the small number of the nations which have formally indicated their inability to officially participate and the large number of persons who will attend as individuals or as representatives of important fishery societies, the congress promises to be important in its representative character, size, and the value of its proceedings.

All persons interested in the fisheries, fish culture, and fishery administration, or in scientific investigations and experiments related to the fisheries are invited to attend the meetings and take part in the discussions. To 